\title{
miR-30a-5p mitigates autophagy by regulating the Beclin-1/ATG16 pathway in renal ischemia/reperfusion injury
}

\author{
YE FANG, LIN ZOU and WEI HE \\ Priority Medical Department, General Hospital of Central Theater Command, Wuhan, Hubei 430070, P.R. China
}

Received September 12, 2020; Accepted April 26, 2021

DOI: $10.3892 / \mathrm{ijmm} .2021 .4977$

\begin{abstract}
Renal ischemia/reperfusion(I/R) injury often occurs during multiple organ failure and sepsis, and autophagy may serve a role in $\mathrm{I} / \mathrm{R}$ injury. The aim of the present study was to explore the effect of microRNA (miR)-30a-5p on autophagy in renal I/R injury. miR-30a-5p and autophagy-related protein expression levels in renal I/R injury mouse models and in hypoxia/re-oxygenation HK-2 cell models were determined using reverse transcription-quantitative PCR or western blotting; apoptosis was analyzed using flow cytometry. The effects of miR-30a-5p, Beclin-1 and autophagy-related gene 16 (ATG16) on the proliferation and autophagy of HK-2 cells were analyzed through gain- and loss-of-function studies. miR-30a-5p expression was significantly decreased after renal $\mathrm{I} / \mathrm{R}$ injury in the in vivo and in vitro experiments. Renal I/R injury led to upregulated expression of autophagy-related proteins microtubule-associated protein light chain 3 (LC3)-II and Beclin-1, and downregulated expression of p62. miR-30a-5p overexpression decreased the number of LC3 punctae, decreased HK-2 cell apoptosis, increased p62 expression and decreased LC3-II and Beclin-1 expression. Inhibition of miR-30a-5p exhibited the opposite effects. A luciferase reporter assay demonstrated that miR-30a-5p targeted Beclin-1. Beclin-1 overexpression led to a significant increase in LC3-II expression and a decrease in p62 expression, as well as a significant increase in apoptosis. Beclin-1 overexpression also increased the protein expression level of ATG16. Downregulation of Beclin-1 decreased the expression of LC3-II, elevated the p62 level and decreased apoptosis. ATG16 knockdown showed similar effects as those of Beclin-1 downregulation. In conclusion, miR-30a-5p was increased in renal I/R injury and might mitigate autophagy by regulating the Beclin-1/ATG16 pathway.
\end{abstract}

Correspondence to: Dr Wei He, Priority Medical Department, General Hospital of Central Theater Command, 627 Wuluo Road, Wuhan, Hubei 430070, P.R. China

E-mail: heweigcc@163.com

Key words: microRNA-30a-5p, autophagy, Beclin-1, renal ischemia/reperfusion injury, autophagy-related gene 16

\section{Introduction}

Acute kidney injury (AKI) is one of the most common clinical syndromes following surgical operations and sepsis; it is accompanied by a disorder in kidney function (1). AKI occurs in $10-15 \%$ of patients admitted to hospital, whereas its incidence in intensive care has been reported in $>50 \%$ of patients. AKI is evaluated by examining the levels of serum creatinine (SCr) and blood urea nitrogen (BUN) (2). Among the etiology of AKI, prerenal etiologies account for 25-60\% and renal etiologies account for 35-70\% of AKI cases (3). In the kidney, proximal tubules are more susceptible to ischemia than are the inner medulla and deep papillae (4). Ischemia/reperfusion (I/R) injury of the kidney is the leading cause of AKI (5). It was reported that ischemic injury or nephrotoxins contribute to $80-90 \%$ of the renal etiologies (3).

Autophagy is a cellular stress response that serves important roles in cellular homeostasis (6,7). Autophagy can be caused by stress, including cell starvation, oxidant injury and endoplasmic reticulum stress, as well as hypoxia $(6,7)$. Most of these stresses occur in the pathogenesis of AKI (8). Accumulating evidence indicates that autophagy may serve a protective role in cell survival during renal ischemia/reperfusion injury $(9,10)$.

MicroRNAs (miRNAs) are a family of small (19-22 nucleotides), non-coding RNAs (11). Previous studies have implicated dysregulated miRNAs in the pathogenesis of kidney injury $(5,12,13)$. miRNA (miR)-30a-5p is a tumor suppressor in several cancer types (14-16). Previous studies have linked miR-30a-5p to ischemic heart disease (17) and cerebral ischemic stroke (18). miR-30a-5p is also reported to regulate renal cell carcinoma aggressiveness (15). However, the function and underlying mechanisms of miR-30a-5p in ischemic kidney injury remain unclear. The present study aimed to explore whether miR-30a-5p affected ischemic kidney injury and the autophagy of tubular epithelial cells, as well as to investigate the underlying mechanism.

\section{Materials and methods}

Animal models. Male C57BL/6 mice (age, 6-8 weeks; weight, 18-22 g) were from Chengdu Dossy Experimental Animals Co., Ltd. The mice were maintained in a temperature $\left(22 \pm 2^{\circ} \mathrm{C}\right)$ and humidity-controlled $(55 \pm 5 \%)$ vivarium with a 12 -h light/dark cycle and allowed free access to food and water. Mice were 
anesthetized with an intraperitoneal injection of pentobarbital $(70 \mathrm{mg} / \mathrm{kg})$ and kept on a warm blanket to maintain the body temperature at $37^{\circ} \mathrm{C}$ during surgery. To induce renal $\mathrm{I} / \mathrm{R}$ injury, the bilateral renal pedicles were clamped for $60 \mathrm{~min}$ with a microaneurysm clip followed by $24 \mathrm{~h}$ reperfusion. For miR-30a-5p detection, mice with $6 \mathrm{~h}$ reperfusion after $60 \mathrm{~min}$ clamping were also used. Mice were sacrificed by cervical dislocation, and their kidneys and blood were collected for examination. Mice in the sham group underwent the same surgical procedures without clamping. The Ethics Committee of the General Hospital of Central Theater Command (Wuhan, China) approved this study, which followed the regulatory standards of the National Institutes of Health guide for the care and use of laboratory animals (19).

For the in vivo study of the function of miR-30a-5p, adenovirus miR-30a-5p mimic (Ad-mimic) and miR-30a-5p inhibitor (Ad-inhibitor) were purchased from Shanghai GenePharma Co. Ltd. Mice were intraperitoneally injected with $1 \times 10^{9} \mathrm{pfu}$ Ad-mimic or Ad-inhibitor $24 \mathrm{~h}$ before renal I/R injury.

Histopathological evaluation. Freshly harvested kidney tissues from mice were fixed in $4 \%$ paraformaldehyde for $16 \mathrm{~h}$ at room temperature. The tissues were then dehydrated through an ethanol gradient. Tissues were paraffin embedded and cut into $5 \mu \mathrm{m}$ sections. The sections were then deparaffinized with xylene and rehydrated in an ethanol gradient and distilled water. The sections were stained with hematoxylin for $5 \mathrm{~min}$, washed with water, differentiated for $30 \mathrm{sec}$ and stained with eosin for $30 \mathrm{sec}$ at room temperature. Histological damage was quantified in a blinded manner using a light microscope. Tubular necrosis scores were determined by assessing the percentage of tubules that displayed epithelial necrosis or had luminal necrotic debris, tubular dilation and hemorrhage: 0 , none; 1 , mild $(<25 \%)$; 2 , moderate $(25-50 \%)$; 3 , severe (51-75\%); and 4 , extensive ( $>75 \%$ ) damage (20).

Detection of SCr, BUN and kidney injury molecule 1 (Kim-1). Serum levels of SCr and BUN were analyzed using commercially available Creatinine Assay kit (cat. no. C011-1-1) and Urea Assay kit (cat. no. C013-2-1) from Nanjing Jiancheng Bioengineering Institute, respectively, according to the manufacturer's procedure. Urine concentrations of Kim-1 were analyzed using commercially Kidney Injury Molecule 1 Assay kit (cat. no. H436-1; Nanjing Jiancheng Bioengineering Institute) according to the manufacturer's procedure.

ELISA analysis. Serum levels of TNF- $\alpha$, IL-1 $\beta$ and IL-6 were determined by commercially available mouse TNF- $\alpha$ ELISA kit (cat. no. PT512), mouse IL-1 $\beta$ ELISA kit (cat. no. PI301) and mouse IL-6 ELISA kit (cat. no. PI326) from Beyotime Institute of Biotechnology, respectively. Absorbance was measured at $450 \mathrm{nM}$ using a microplate reader (Bio-Rad Laboratories, Inc.). All samples were analyzed in triplicate.

Cell lines. HK-2 human tubular epithelial and 293T cell lines were obtained from the American Type Culture Collection (ATCC) and were cultured according to ATCC protocols. Both cell lines were cultured in DMEM supplemented with $10 \%$ fetal bovine serum (Gibco; Thermo Fisher Scientific, Inc.), streptomycin $(100 \mu \mathrm{g} / \mathrm{ml})$, penicillin $(100 \mathrm{U} / \mathrm{ml})$ and
$2 \mathrm{mM}$ of L-glutamate. All cells were cultured at $37^{\circ} \mathrm{C}$ in a $5 \% \mathrm{CO}_{2}$ incubator (Thermo Fisher Scientific, Inc.). To induce hypoxia/re-oxygenation (H/R) injury, HK-2 cells were incubated in a hypoxic chamber with $0.3 \% \mathrm{O}_{2}, 5 \% \mathrm{CO}_{2}$, and $95 \% \mathrm{~N}_{2}$ for $16 \mathrm{~h}$, and then were re-oxygenated in a normoxic chamber with $5 \% \mathrm{CO}_{2}$ and $95 \% \mathrm{~N}_{2}$ for $4 \mathrm{~h}$.

Reverse transcription-quantitative PCR (RT-qPCR). Total RNA was extracted from renal cortex tissues and cells using a RNeasy mini kit (Qiagen Sciences, Inc.) according to the manufacturer's protocols. cDNA was synthesized using the SuperScript III First-Strand Synthesis kit (Invitrogen; Thermo Fisher Scientific, Inc.) in accordance with the manufacturer's instructions. qPCR was performed using TaqMan Master Mix (Applied Biosystems; Thermo Fisher Scientific, Inc.) and an ABI 7300 Real Time PCR System (Applied Biosystems; Thermo Fisher Scientific, Inc.). The thermocycling conditions were as follows: Initial denaturation at $95^{\circ} \mathrm{C}$ for $10 \mathrm{~min}$; followed by 40 cycles of denaturation at $95^{\circ} \mathrm{C}$ for $10 \mathrm{sec}$, annealing and extension at $60^{\circ} \mathrm{C}$ for $1 \mathrm{~min}$. The following primers were used: miR-30a-5p, forward 5'-TGTAAACAT CCTCGACTGGAAG-3' and reverse 5'-TGCGTGTCGTGG AGTC-3'; U6, forward 5'-CTCGCTTCGGCAGCACA-3' and reverse 5'-AACGCTTCACGAATTTGCGT-3'; Beclin-1, forward 5'-AGGTTGAGAAAGGCGAGACA-3' and reverse 5'-TTTTGATGGAATAGGAGCCG-3'; and $\beta$-actin, forward 5'-GTGGGCCGCCCTAGGCACCA-3' and reverse 5'-CGG TTGGCCTTAGGGTTCAG-3'. $\beta$-actin or U6 were used as the internal controls. Relative expression levels were analyzed using $2^{-\Delta \Delta C q}$ method (21).

Western blotting. Proteins were obtained from mouse renal cortex and HK-2 cells using RIPA lysis buffer (Beijing Solarbio Science \& Technology Co., Ltd.). Protein concentration was measured with a BCA Protein Assay kit (cat. no. P0011; Beyotime Institute of Biotechnology). Equal amounts $(30 \mu \mathrm{g})$ of protein from each sample were separated by $10 \%$ SDS-PAGE. The separated bands were then electrotransferred onto a polyvinylidene difluoride membrane (Roche Diagnostics). After being blocked with 5\% skim milk on a rotary shaker at room temperature for $2 \mathrm{~h}$, the blots were incubated with the following primary antibodies: Rabbit anti-human microtubule-associated protein light chain 3 (LC3)-I/II monoclonal antibody (1:2,000; cat. no. 12741; Cell Signaling Technology, Inc.), rabbit anti-human Beclin-1 monoclonal antibody (1:1,500; cat. no. 3495; Cell Signaling Technology, Inc.), rabbit anti-human p62 monoclonal antibody (1:2,000; cat. no. ab207305; Abcam), rabbit anti-human autophagy-related gene16 (ATG16) monoclonal antibody (1:2,000; cat. no. 8089; Cell Signaling Technology, Inc.), and mouse anti-human $\beta$-actin $(1: 2,500$; cat. no. ab8226; Abcam) overnight at $4^{\circ} \mathrm{C}$, followed by horseradish peroxidase (HRP)-conjugated goat anti-mouse $\operatorname{IgG}(1: 10,000$; cat. no. ab6789; Abcam) or HRP-conjugated goat anti-rabbit IgG (1:10,000; cat. no. ab6721; Abcam) for $30 \mathrm{~min}$ at $37^{\circ} \mathrm{C}$. Protein bands were visualized using ECL Western Blotting Substrate kit (cat. no. 32209; Pierce; Thermo Fisher Scientific, Inc.) and semi-quantified using the ImageJ software (version 1.47; National Institutes of Health); $\beta$-actin was used for normalization. 
Cell transfection. miR-30a-5p mimic (sense, 5'-UGUAAA CAUCCUCGACUGGAAG-3'; anti-sense, 5'-CUUCCAGUC GAGGAUGUUUACA-3'), miR-30a-5p inhibitor (5'-CUU CCAGUCGAGGAUGUUUACA-3'), miRNA mimic-negative control (nc) (sense, 5'-UCACAACCUCCUAGAAAGAGU AGA-3'; anti-sense, 5'-UACUCUUUCUAGGAGGUUGUG AUU-3') and inhibitor-nc (5'-CACAUUGTGCUCUCUGCA CUGCTC-3'), Beclin-1 small interfering (si)RNA (sense, 5'-GGAGCCAUUUAUUGAAACUTT-3'; anti-sense, 5'-AGU UUCAAUAAAUGGCUCCTT-3'), siRNA-scramble control (sense, 5'-GUACGCCAAAAGUUAAACC-3', anti-sense, 5'-GGUUUAACUUUUGGCGUAC-3') and ATG16 siRNA (sense, 5'-AGAGCUUGACUCAGACCAAGU-3'; anti-sense, 5'-UUGGUCUGAGUCAAGCUCUGA-3') were purchased from Shanghai GenePharma Co. Ltd. Beclin-1 cDNA was amplified from the HK-2 cells and cloned into the pcDNA3.1 vector (Invitrogen; Thermo Fisher Scientific, Inc.). For miR-30a-5p function analysis, $3 \times 10^{5}$ HK-2 cells were transfected with miR-30a-5p mimic ( $50 \mathrm{nM})$, miR-30a-5p inhibitor $(100 \mathrm{nM})$, miRNA-nc $(50 \mathrm{nM})$ or inhibitor-nc $(100 \mathrm{nM})$ using Lipofectamine ${ }^{\circledR} 2000$ (Invitrogen; Thermo Fisher Scientific, Inc.) for $48 \mathrm{~h}$. To downregulate the expression of Beclin-1 or ATG16, $3 \times 10^{5}$ HK-2 cells were transfected with siRNA-scramble control $(50 \mathrm{nM})$, Beclin-1 siRNA $(50 \mathrm{nM})$ or ATG16 siRNA (50 nM) using Lipofectamine ${ }^{\circledR} 2000$ for $48 \mathrm{~h}$. To overexpress Beclin-1, 3x10 ${ }^{5}$ HK-2 cells were transfected with pcDNA3.1 empty vector $(0.5 \mu \mathrm{g})$ or pcDNA3.1-Beclin-1 $(0.5 \mu \mathrm{g})$ using Lipofectamine ${ }^{\circledR} 2000$ for $48 \mathrm{~h}$.

Flow cytometry. Apoptosis was detected using the Annexin V-FITC Apoptosis Detection kit (cat. no. C1062L; Beyotime Institute of Biotechnology) according to previously reported protocols (22). Briefly, cells $\left(1 \times 10^{6}\right)$ were re-suspended in $100 \mu \mathrm{l}$ binding buffer. Annexin V-FITC (5 $\mu \mathrm{l})$ and propidium iodide staining solution $(10 \mu \mathrm{l})$ were added to the cell suspension and the cells were cultured in the dark for $15 \mathrm{~min}$ at room temperature. The percentage of early + late stage apoptotic was detected using a BD FACSCalibur flow cytometer (BD Biosciences), and data were analyzed using FlowJo 7.6.1 (FlowJo LLC).

Immunofluorescence staining. Immunofluorescence staining of LC3 was performed according to previously described methods (23). Briefly, $3 \times 10^{5}$ cells were fixed with $4 \%$ paraformaldehyde for $20 \mathrm{~min}$ at room temperature, permeabilized with $0.02 \%$ Triton X-100 for $5 \mathrm{~min}$ at room temperature, blocked with 5\% bovine serum albumin (Beyotime Institute of Biotechnology) in PBS for $20 \mathrm{~min}$ at $4^{\circ} \mathrm{C}$ and incubated with rabbit anti-human LC3 monoclonal antibody $(1: 1,000$; cat. no. 3868; Cell Signaling Technology, Inc.) for $12 \mathrm{~h}$ at $4^{\circ} \mathrm{C}$. After washing three times with PBS, cells were incubated with the Alexa Fluor 488-conjugated goat anti-rabbit IgG secondary antibody (1:200; cat. no. A-11034; Thermo Fisher Scientific, Inc.) for $2 \mathrm{~h}$. Images were captured using fluorescence microscopy (Zeiss AG). The number of LC3 punctae in each cell were counted. A minimum of 50 cells were included for each group.

In silico analysis. The predicted targets of miR-30a-5p were analyzed by the EIMMo miRNA target prediction server (24),
microRNA.org database (25), and TargetScan (Release 7.2: March 2018; http://www.targetscan.org) database.

Luciferase reporter assay. The pGLO-Beclin-1-wild-type (WT) plasmids were constructed by cloning the 3 '-untranslated region (3'-UTR) of Beclin-1 containing the predicted miR-30a-5p binding site downstream of the firefly luciferase structural gene of the pmirGLO Dual-Luciferase miRNA Target Expression Vector (Promega Corporation). Similarly, the mutant (Mut) 3'-UTR of Beclin-1 was generated using a QuikChange Site-Directed Mutagenesis kit (Agilent Technologies, Inc.), according to the manufacturer's protocol, and used to make the pGLO-Beclin-1-Mut plasmids. The 293T cells were plated into 24 -well plates $\left(1.5 \times 10^{5}\right.$ cells/well $)$ and incubated at $37^{\circ} \mathrm{C}$ for $24 \mathrm{~h}$. Subsequently, the cells were transfected at $37^{\circ} \mathrm{C}$ with $100 \mathrm{nM}$ miR-30a-5p or a mimic-nc combined with 100 ng pGLO-Beclin-1-WT or pGLO-Beclin-1-Mut plasmid using Lipofectamine ${ }^{\circledR} 2000$ (Invitrogen; Thermo Fisher Scientific, Inc.). At $48 \mathrm{~h}$ after transfection, luciferase activities were measured using a Dual-Luciferase Reporter Assay kit (Promega Corporation) according to the manufacturer's instructions using a GloMax 20/20 luminometer (Promega Corporation). The relative luciferase activity was normalized by Renilla luciferase activity.

RNA immunoprecipitation (RIP). RIP was performed using an EZ-Magna RIP RNA-Binding Protein Immunoprecipitation kit (cat. no. 17-701; MilliporeSigma) in HK-2 cells transfected with miR-30a-5p mimic or mimic-nc. $5 \times 10^{6}$ cells were lysed with complete RIP lysis buffer. Subsequently, $100 \mu 1$ of cell lysate was incubated with RIP buffer containing magnetic beads conjugated with mouse anti-human ago 2 antibody (1:10; cat. no. MA5-23515; Thermo Fisher Scientific, Inc.) or negative control normal mouse IgG (1:10; cat. no. ab188776; Abcam). Samples were incubated with Proteinase K buffer, washed with RIP Wash Buffer, and then the bound RNA was extracted with phenol:chloroform:isoamyl alcohol (25:24:1, v/v) for RT-qPCR assay, aforementioned.

Statistical analysis. All statistical analyses were conducted using SPSS 20.0 software (IBM Corp.). Data are expressed as the mean \pm standard deviation. Differences between two groups were assessed using an independent samples t-test. For multiple-group comparisons, a significant one-way analysis of variance F-test was used, followed by the Tukey-Kramer test. $\mathrm{P}<0.05$ was considered to indicate a statistically significant difference.

\section{Results}

miR-30a-5p expression is decreased in mouse models of renal $I / R$ injury and in $H / R$-exposed $H K-2$ cells. To induce renal I/R injury, the bilateral renal pedicles were clamped for $60 \mathrm{~min}$ with a microaneurysm clip followed by $24 \mathrm{~h}$ reperfusion (model group). Mice were subsequently euthanized, and their kidneys and blood were collected for examination. Mice in the sham group underwent the same surgical procedures without clamping. Compared with the sham surgery group, the mouse models of renal I/R injury exhibited significantly increased serum levels of $\mathrm{SCr}$, BUN and urine concentrations 

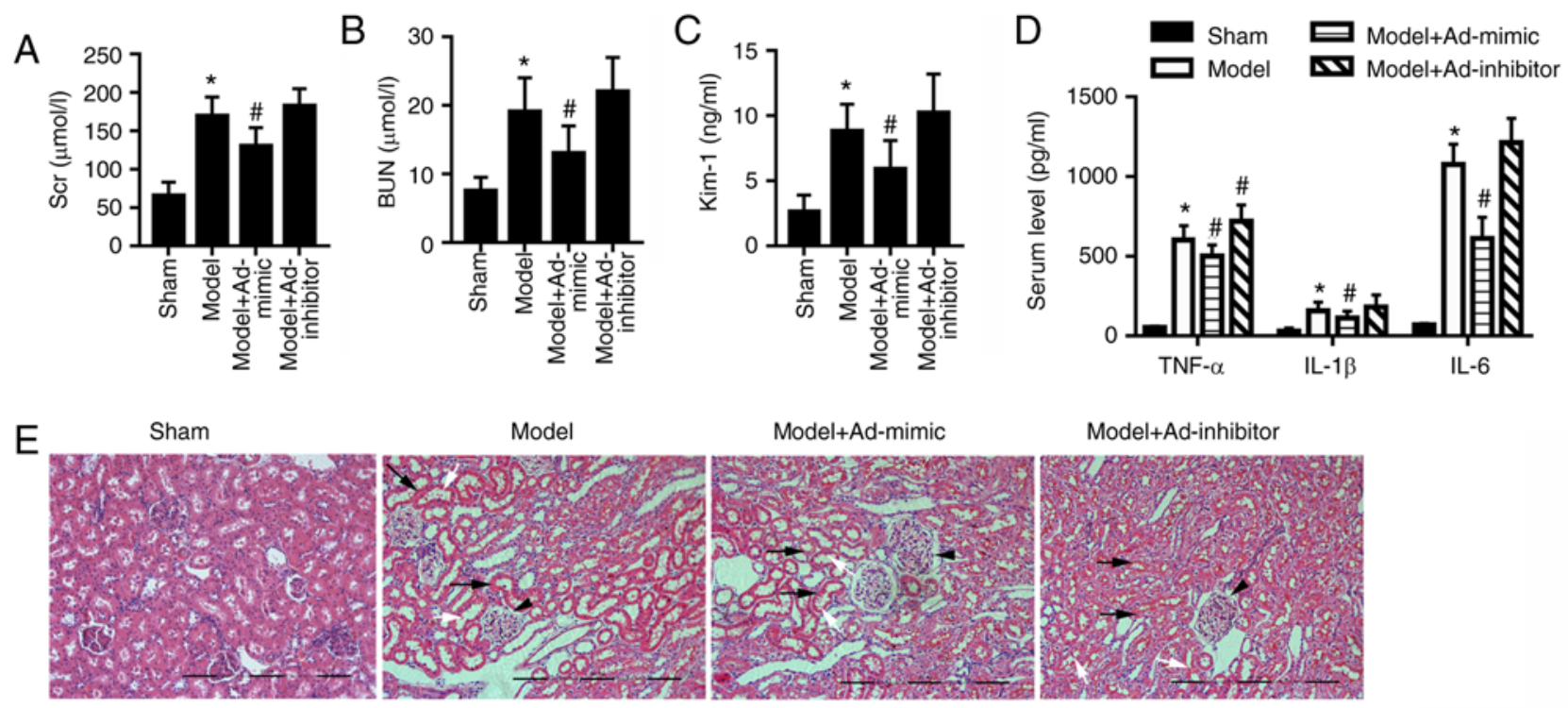

Model+Ad-inhibitor
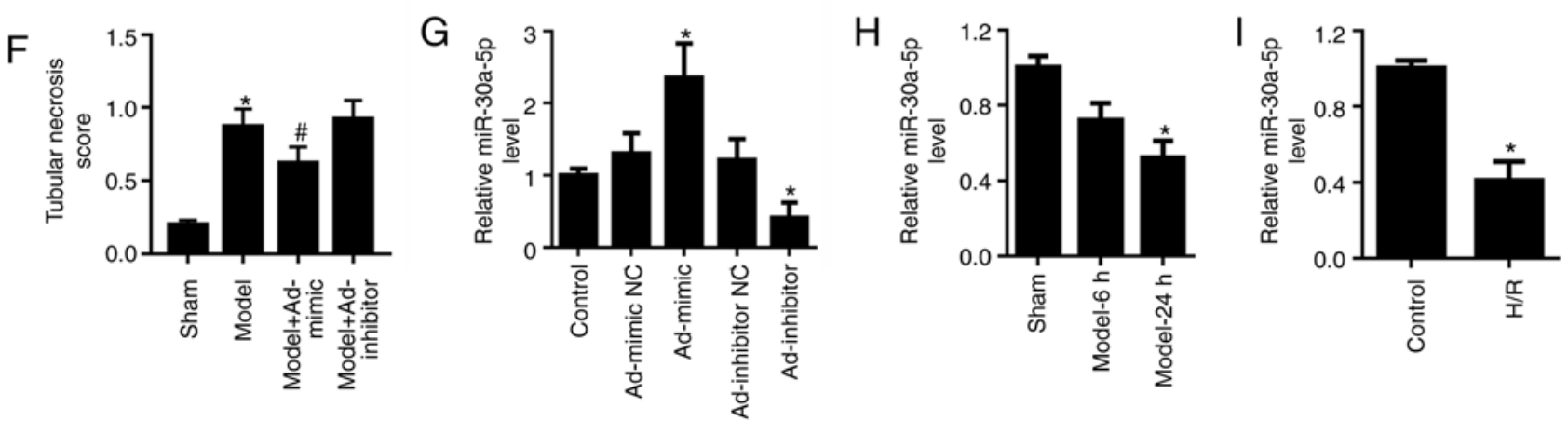

Figure 1. miR-30a-5p expression is decreased in in vivo and in vitro models of renal I/R injury. Mice were intraperitoneally injected with Ad-mimic or Ad-inhibitor $24 \mathrm{~h}$ before renal ischemia/reperfusion injury. ELISA analysis for serum levels of (A) SCr and (B) BUN, and (C) urine concentration of Kim-1 in mice (n=6). (D) ELISA analysis for serum levels of TNF- $\alpha$, IL-1 $\beta$ and IL-6. (E) Renal histological changes in mice were observed by H\&E staining; scale bar, $40 \mu \mathrm{m}$. Black arrows indicate the loss of epithelial cell nuclei; white arrows point to abscission of tubular epithelial cells; and black arrowheads indicate glomerular hypertrophy. (F) The histological tubular necrosis scores were evaluated. (G) miR-30a-5p expression levels in the cortex region of mouse kidneys following intraperitoneal injection with Ad-mimic or Ad-inhibitor were detected by RT-qPCR. (H) miR-30a-5p expression levels in the renal cortex region of mice was detected using RT-qPCR at 6 and $24 \mathrm{~h}$ post-reperfusion $(\mathrm{n}=6)$. (I) miR-30a-5p expression in H/R-exposed HK-2 cells was assessed by RT-qPCR $(\mathrm{n}=3)$. " $\mathrm{P}<0.05$ vs. sham or control; ${ }^{*} \mathrm{P}<0.05$ vs. model. Ad, adenovirus; $\mathrm{H} / \mathrm{R}$, hypoxia/reoxygenation; Kim-1, kidney injury molecule 1 ; miR, microRNA; RT-qPCR, reverse transcription-quantitative PCR; BUN, blood urea nitrogen; SCr, serum creatinine.

of Kim-1 (Fig. 1A-C, respectively). To assess the levels of inflammation during injury, the concentrations of TNF- $\alpha$, IL-1 $\beta$ and IL-6 were also examined using ELISA kit. The result showed that serum levels of TNF- $\alpha$, IL- $1 \beta$ and IL- 6 were significantly elevated after renal I/R compared with the sham group (Fig. 1D). Histopathological examination revealed tubular epithelial cell necrosis in renal I/R injury model group, including abscission of tubular epithelial cells, glomerular hypertrophy and loss of epithelial cell nuclei (Fig. 1E and F). These results confirmed the successful establishment of the mouse models of kidney injury.

For the in vivo study of the function of miR-30a-5p, model mice were intraperitoneally injected with Ad-mimic or Ad-inhibitor $24 \mathrm{~h}$ before renal I/R injury. miR-30a-5p expression levels in the cortex region of were detected by RT-qPCR, which demonstrated that miR-30a-5p was significantly upregulated by Ad-mimic injection and was significantly downregulated by Ad-inhibitor injection compared with control group (Fig. 1G). The result showed that miR-30a-5p overexpression partially relieved renal $\mathrm{I} / \mathrm{R}$ injury in vivo, whereas miR-30a-5p knockdown exhibited less effect on serum levels of SCr, BUN, TNF- $\alpha$, IL- $1 \beta$ and IL-6, urine concentrations of Kim-1 and tubular necrosis score in the renal $\mathrm{I} / \mathrm{R}$ injury mouse models compared with the untreated model group (Fig. 1A-F). In the cortex region of mice with renal I/R injury, miR-30a-5p expression decreased compared with the sham group (Fig. 1H). Consistent with the results of the in vivo experiments, miR-30a-5p expression was also significantly decreased in the H/R-exposed HK-2 cells as compared with the control cells (Fig. 1I).

miR-30a-5p suppresses autophagy and apoptosis in renal $I / R$ injury. Compared with those of the sham group, the cortex region of mice with renal I/R injury exhibited an upregulation in the protein expression levels of autophagy-related proteins LC3-II and Beclin-1, and downregulated expression of p62 (Fig. 2A). Ad-mimic infection reduced the expression of LC3-II and Beclin-1 but increased the expression of p62 compared with the model group (Fig. 2A). Ad-inhibitor infection increased the expression of LC3-II and decreased the expression of p62 compared with the model group (Fig. 2A); however, no significant difference was detected for the 

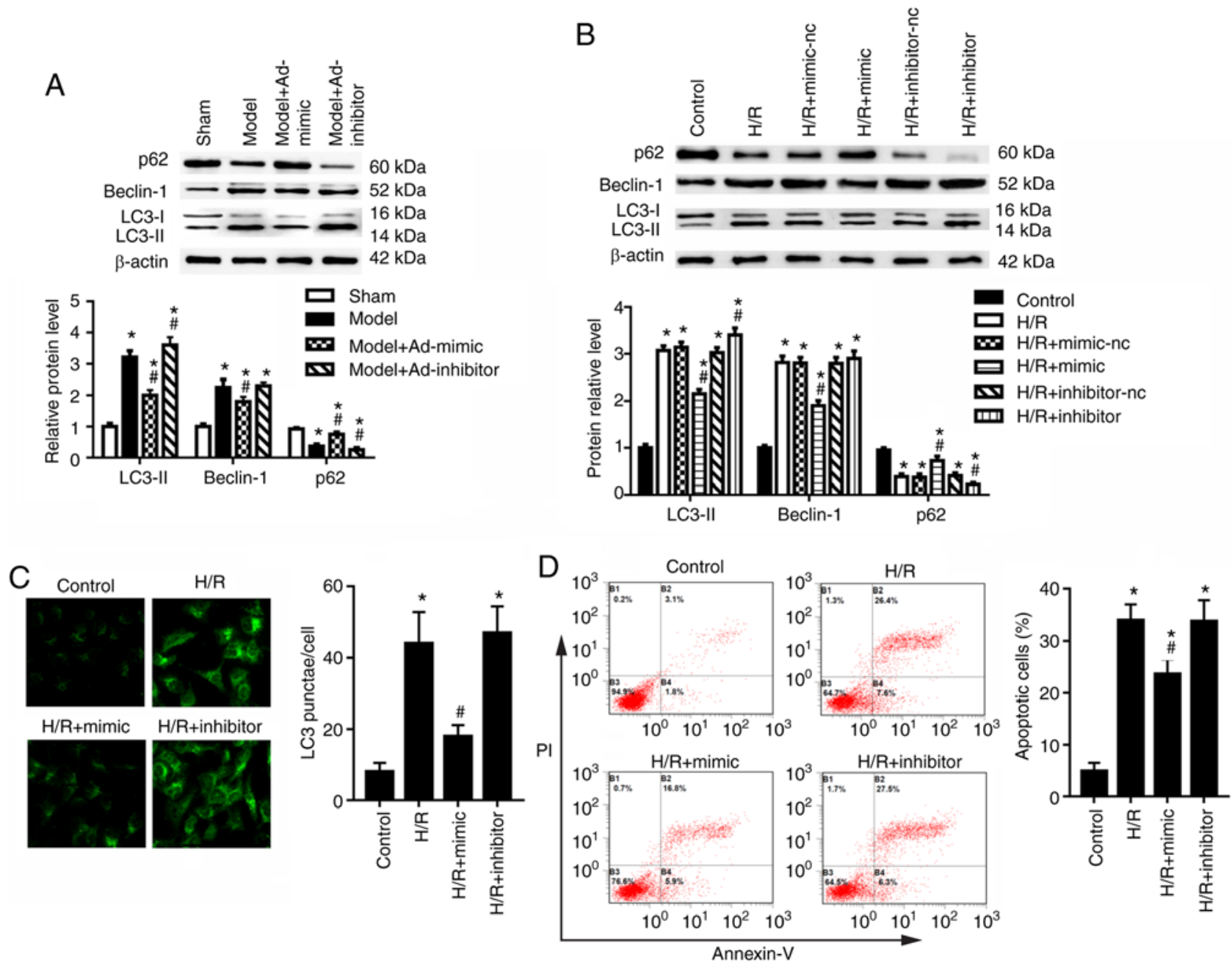

Figure 2. miR-30a-5p regulates autophagy in HK-2 cells under H/R injury. (A) I/R model mice were intraperitoneally injected with Ad-mimic or Ad-inhibitor $24 \mathrm{~h}$ before renal I/R injury. Western blot analysis was used to determine the protein expression levels of LC3-I-II, Beclin-1 and p62 in the renal cortex ( $\mathrm{n}=6$ ). ${ }^{*} \mathrm{P}<0.05$ vs. sham; ${ }^{\text {} P} \mathrm{P}<0.05$ vs. model. (B) HK-2 cells were transfected with miR-30a-5p mimic or miR-30a-5p inhibitor, and the protein expression levels of LC3, Beclin-1 and p62 were measured in HK-2 cells $(n=3)$. ${ }^{*} \mathrm{P}<0.05$ vs. control; ${ }^{*} \mathrm{P}<0.05 \mathrm{vs}$. H/R. (C) Immunofluorescence staining was performed to detect LC3 punctae in HK-2 cells under H/R injury with the use of miR-30a-5p mimic or miR-30a-5p inhibitor ( $\mathrm{n}=3$; magnification, $\mathrm{x} 40$ ). ${ }^{*} \mathrm{P}<0.05$ vs. control; ${ }^{\#} \mathrm{P}<0.05$ vs. $\mathrm{H} / \mathrm{R}$. (D) Apoptosis was analyzed by flow cytometry following staining for Annexin V-FITC/PI ( $n=3$ ). ${ }^{*} \mathrm{P}<0.05$ vs. control, " $\mathrm{P}<0.05$ vs. $\mathrm{H} / \mathrm{R}$. Ad, adenovirus; $\mathrm{H} / \mathrm{R}$, hypoxia/reoxygenation; I/R, ischemia/reperfusion; LC3, microtubule-associated protein light chain 3; miR, microRNA; nc, negative control.

expression levels of Beclin-1. In the HK-2 cells, miR-30a-5p mimic transfection significantly increased and miR-30a-5p inhibitor transfection significantly decreased the expression levels of miR-30a-5p (Fig. S1). Moreover, HK-2 cells in the $\mathrm{H} / \mathrm{R}$ condition showed significantly increased LC3-II and Beclin-1 levels, and decreased p62 level, compared with the control group (Fig. 2B). To confirm the effects of miR-30a-5p on the pathogenesis of renal $\mathrm{I} / \mathrm{R}$ injury, HK-2 cells were transfected with miR-30a-5p mimic or miR-30a-5p inhibitor and were then exposed to $H / R$. Compared with $H / R$-injured cells, miR-30a-5p overexpression decreased LC3-II and Beclin-1 protein expression levels but increased p62 expression in HK-2 cells (Fig. 2B). miR-30a-5p knockdown increased LC3-II and decreased p62 expression but had no significant effect on Beclin-1 expression compared with the H/R group. LC3 punctae analysis was performed using immunofluorescence staining; the data showed that the number of LC3 punctae was significantly elevated in H/R-exposed HK-2 cells compared with the control cells (Fig. 2C). Transfection of miR-30a-5p mimic significantly decreased the number of punctae compared with the H/R group, whereas miR-30a-5p inhibitor exhibited no significant effect of number of LC3 punctae under H/R condition (Fig. 2C). Following H/R exposure, apoptotic rates significantly increased compared with the control group (Fig. 2D); miR-30a-5p mimic transfection significantly decreased cell apoptosis compared with the H/R group, whereas the miR-30a-5p inhibitor had little effect on cell apoptosis. These results suggested that miR-30a-5p may suppress autophagy and apoptosis under H/R injury.

miR-30a-5p directly interacts with Beclin-1. Beclin-1 was reported to be closely related to cell autophagy (26). Bioinformatics analysis demonstrated Beclin-1 to be a potential target of miR-30a-5p (Fig. 3A). The dual-luciferase reporter assay demonstrated that, compared with the miR-30a-5p mimic-nc, the miR-30a-5p mimic resulted in an $\sim 60 \%$ reduction in the luciferase activity of $293 \mathrm{~T}$ cells transfected with the pGLO-Beclin-1-WT plasmid (Fig. 3B); however, the miR-30a-5p mimic did not affect the luciferase activity of 293T cells that were transfected with the pGLO-Beclin-1-Mut 


\section{A hsa-miR-30-5p 3' gagaaucagcuccUACAAAUGu $5^{\prime}$ IIIIIIII Beclin-1-WT 5' uauuaaacaguacAUGUUUACa $3^{\prime}$ Beclin-1-Mut 5' uauuaaacaguacAUCUAAACa 3'}
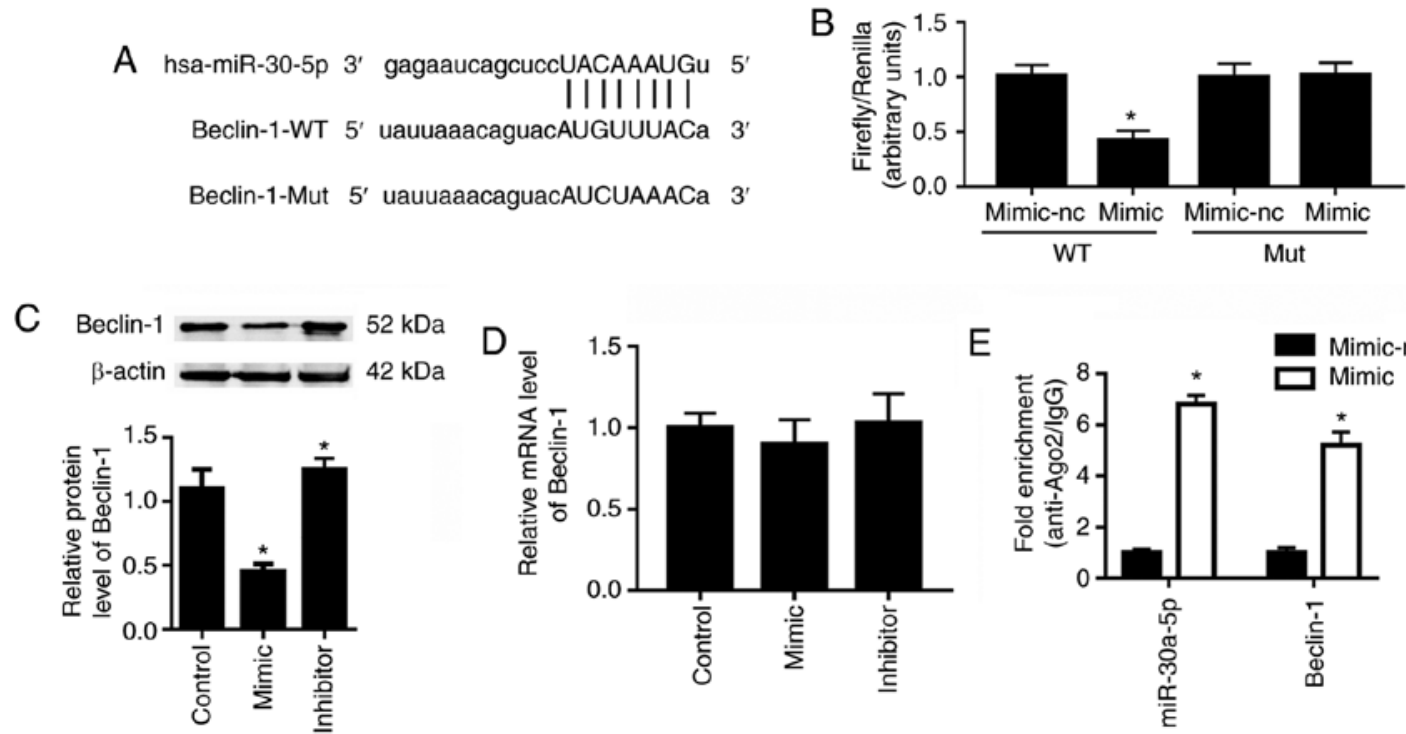

$52 \mathrm{kDa}$

$42 \mathrm{kDa}$
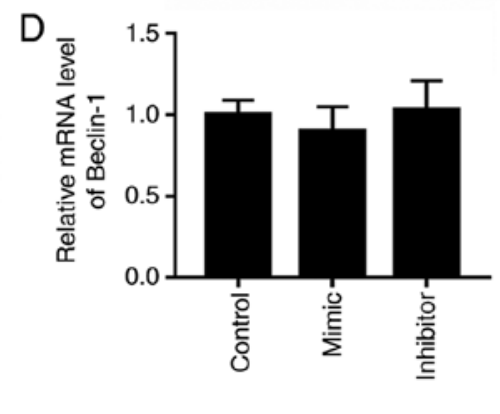

$\mathrm{E}$

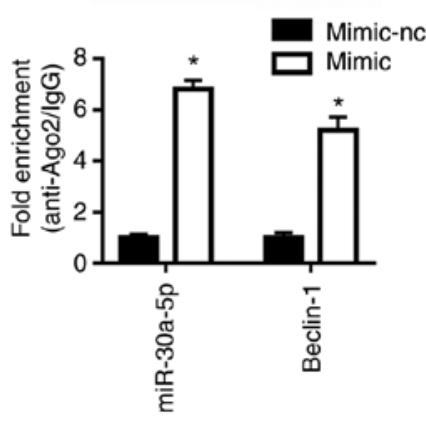

Figure 3. miR-30a-5p directly interacts with the 3'UTR of Beclin-1. (A) The potential binding sites of miR-30a-5p and the 3'UTR of Beclin-1. (B) 293T cells were co-transfected with the pGLO-Beclin-1-WT or pGLO-Beclin-1-Mut plasmid and miR-30a-5p mimic or miR-30a-5p mimic-nc, and luciferase activity was detected $(n=3)$. (C) HK-2 cells were transfected with a miR-30a-5p mimic or miR-30a-5p inhibitor, and the protein levels of Beclin-1 were determined by western blot and semi-quantified. The untransfected cells were used in control group $(\mathrm{n}=3)$. (D) mRNA expression levels of Beclin-1 were detected by RT-qPCR (E) RNA immunoprecipitation assay was performed using anti-Ago2 in HK-2 cells transfected with miR-30a-5p mimic or mimic-nc. miR-30a-5p and 3'UTR of Beclin-1 mRNA expression levels in the anti-Ago2 immunoprecipitated products were measured by RT-qPCR. "P<0.05 vs. miR-30a-5p mimic-nc or control group. miR, microRNA; Mut, mutant; nc, negative control; RT-qPCR, reverse transcription-quantitative PCR; UTR, untranslated region; WT, wild-type.

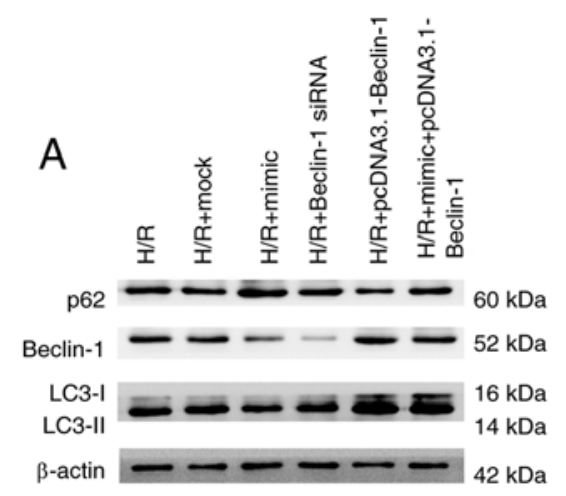

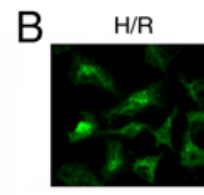

$\mathrm{H} / \mathrm{R}+$
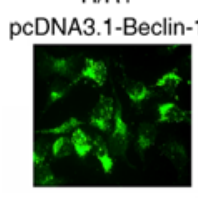

pcDNA3.1-Beclin-1

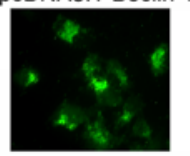

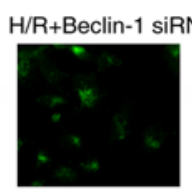

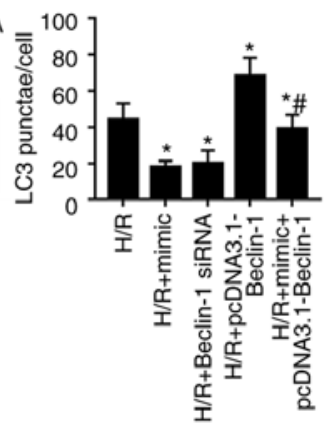

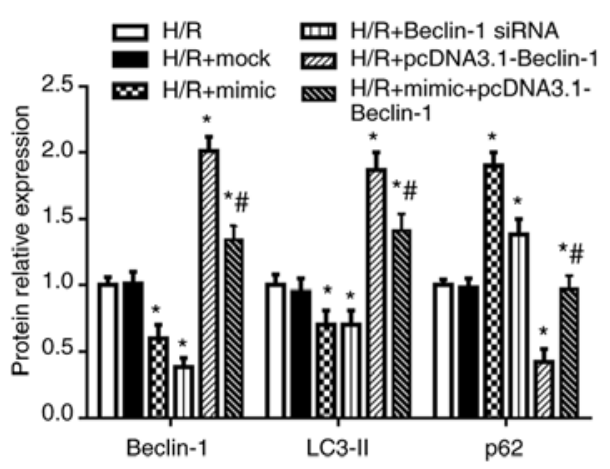
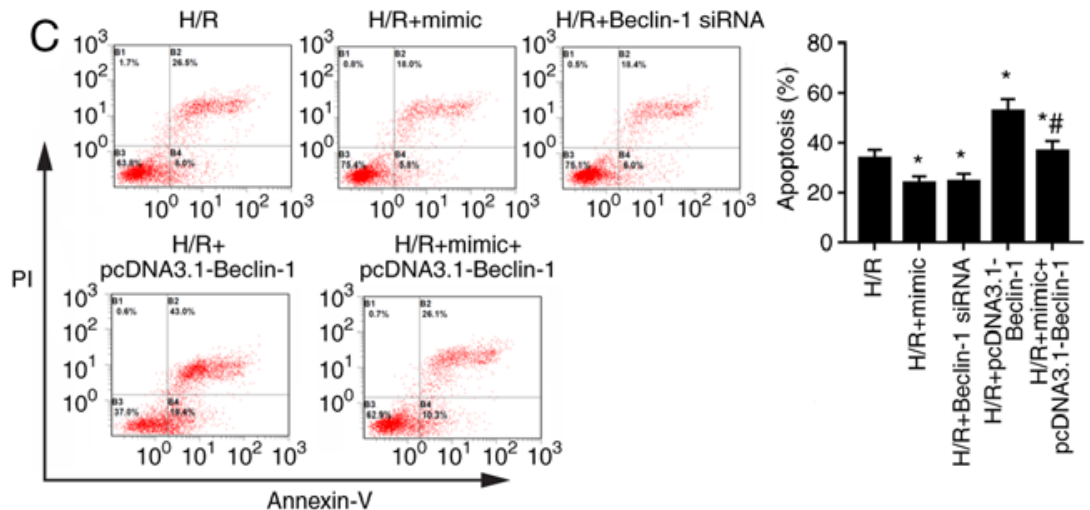

Figure 4. Beclin-1 serves a crucial role in autophagy in HK-2 cells. (A) HK-2 cells were transfected with miR-30a-5p mimic, Beclin-1 siRNA, pcDNA3.1-Beclin-1 or a combination of the miR-30a-5p mimic with pcDNA3.1-Beclin-1 for $48 \mathrm{~h}$ and then exposed to H/R. The protein expression levels of Beclin-1, LC3-II and p62 were measured by western blot and semi-quantified $(n=3)$. (B) Immunofluorescence staining was performed to detect LC3 punctae in HK-2 cells $(n=3$; magnification, x40). (C) Cell apoptosis was analyzed by flow cytometry following staining for Annexin V-FITC/PI. ${ }^{*} \mathrm{P}<0.05 \mathrm{vs}$. H/R; ${ }^{*} \mathrm{P}<0.05 \mathrm{vs}$. H/R + pcDN A3.1-Beclin-1. H/R, hypoxia/reoxygenation; LC3, microtubule-associated protein light chain 3; miR, microRNA; siRNA, small interfering RNA.

plasmid. Western blot analysis showed that the miR-30a-5p mimic transfection significantly reduced the protein expression level of Beclin-1, whereas miR-30a-5p inhibitor transfection significantly upregulated Beclin-1 protein levels compared 
with the control group (Fig. 3C). However, neither miR-30a-5p mimic nor inhibitor transfection affected the mRNA expression levels of Beclin-1 significantly compared with the control group (Fig. 3D). To confirm the direct interaction between miR-30a-5p and Beclin-1, RIP assays were conducted. As shown in Fig. 3E, expression levels of miR-30a-5p and 3'UTR of Beclin-1 mRNA in the Ago2-RIP products of miR-30a-5p mimic transfected HK-2 cells were both significantly increased compared to the mimic-nc group.

Beclin-1 serves a crucial role in HK-2 cell autophagy. To investigate the role of Beclin-1 in autophagy of HK-2 cells under $\mathrm{H} / \mathrm{R}$ condition, cells were transfected with miR-30a-5p mimic, Beclin-1 siRNA, pcDNA3.1-Beclin-1 or a combination of the miR-30a-5p mimic with pcDNA3.1-Beclin-1 for $48 \mathrm{~h}$ and then exposed to H/R. Beclin-1 siRNA transfection significantly decreased and pcDNA3.1-Beclin-1 transfection significantly increased the mRNA and protein expression levels of Beclin-1 compared with the control group (Fig. S2A and B). In HK-2 cells under $\mathrm{H} / \mathrm{R}$ condition, Beclin-1 siRNA significantly decreased and pcDNA3.1-Beclin-1 significantly increased Beclin-1 expression compared with the H/R group (Fig. 4A). Compared with cells in the H/R group, Beclin-1 siRNA significantly inhibited expression of LC3-II and increased p62 expression. Conversely, pcDNA3.1-Beclin-1 transfection led to increased LC3-II and decreased p62 expression (Fig. 4A). miR-30a-5p mimic transfection partly reversed the effects of pcDNA3.1-Beclin-1 on the expression of LC3-II, Beclin-1 and p62. LC3 puncta analysis using immunofluorescence staining showed that the number of LC3 punctae was significantly decreased by Beclin-1 knockdown and increased by Beclin-1 overexpression compared with the H/R group (Fig. 4B). Co-transfection of miR-30a-5p mimic combined with Beclin-1 overexpression decreased the number of LC3 puncta compared with the Beclin-1 overexpression group (Fig. 4B). Beclin-1 siRNA transfection also significantly decreased cell apoptosis, whereas Beclin-1 overexpression significantly increased cell apoptosis, compared with cells in the H/R group (Fig. 4C). Co-transfection of miR-30a-5p mimic and pcDNA3.1-Beclin-1 significantly reduced cell apoptosis compared with the Beclin-1 overexpression group. These data indicate that Beclin-1 may serve a crucial role in autophagy of HK-2 cells.

Beclin-1 contributes to HK-2 cell autophagy by modulating ATG16 expression. A previous study demonstrated that ATG16 serves a crucial role in ischemic kidney injury (27). We hypothesized that miR-30a-5p may regulate HK-2 cell autophagy and proliferation by suppressing Beclin-1 expression and ATG16 expression. As expected, in the ischemic kidney injury mouse models and in the H/R-exposed HK-2 cells, ATG16 expression was significantly upregulated (Fig. 5A and B). In the H/R-exposed HK-2 cells, it was revealed that Beclin-1 siRNA decreased and pcDNA3.1-Beclin-1 increased the expression levels of ATG16, compared with the H/R group (Fig. 5C). In addition, miR-30a-5p mimic transfection significantly downregulated, whereas miR-30a-5p inhibitor increased ATG16 expression in H/R-injured HK-2 cells.

The effects of ATG16 on autophagy and apoptosis of HK-2 cells were examined following transfection with ATG16 siRNA, which was used to downregulate ATG16 expression (Fig. S3).
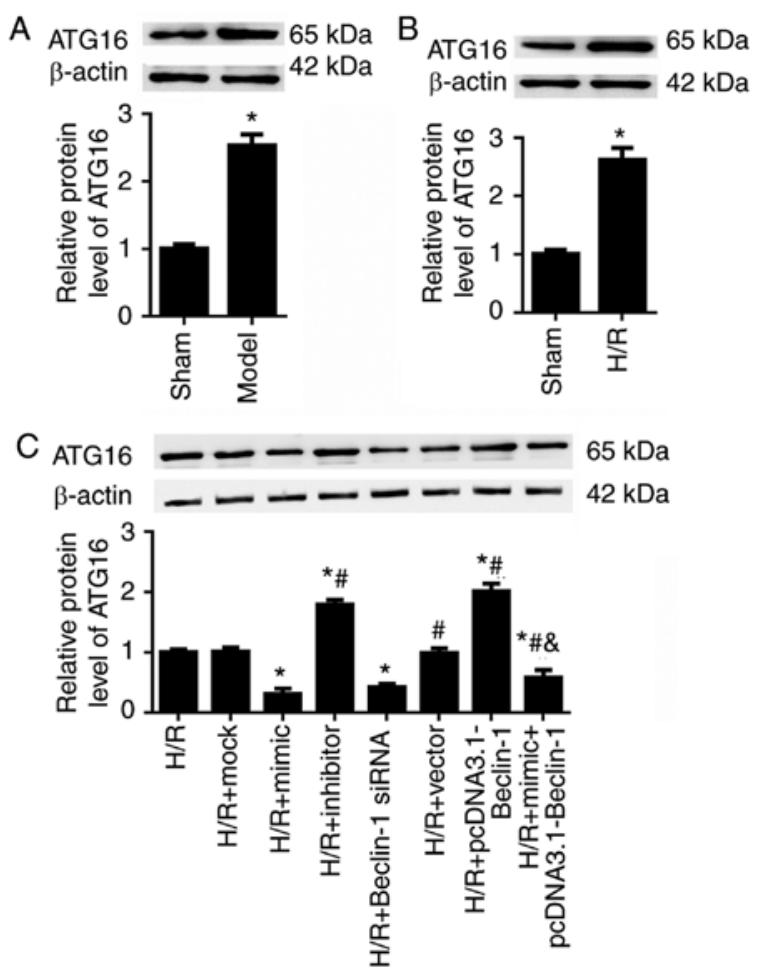

Figure 5. ATG16 expression is modulated by Beclin-1. ATG16 protein expression levels in the (A) renal cortex of IR model mice $(n=6)$ and $(B) H / R$-exposed HK-2 cells $(n=3)$ were detected by western blot. ${ }^{*} \mathrm{P}<0.05$ vs. sham or control. (C) ATG16 protein expression was analyzed by western blot in HK-2 cells transfected with miR-30a-5p mimic, miR-30a-5p inhibitor, Beclin-1 siRNA, pcDNA3.1-Beclin-1 or a combination of the miR-30a-5p mimic with pcDNA3.1-Beclin-1 for $48 \mathrm{~h}$, followed by exposure to $\mathrm{H} / \mathrm{R}$ ( $\mathrm{n}=3$ ). ${ }^{*} \mathrm{P}<0.05$ vs. H/R; ${ }^{\#} \mathrm{P}<0.05$ vs. $\mathrm{H} / \mathrm{R}+\mathrm{mimic} ;{ }^{\circledR} \mathrm{P}<0.05$ vs. H/R + inhibitor. ATG16, autophagy-related gene16; H/R, hypoxia/reoxygenation; miR, microRNA; siRNA, small interfering RNA.

In $\mathrm{HK}-2$ cells under $\mathrm{H} / \mathrm{R}$ condition, ATG16 knockdown significantly decreased ATG16 and LC3-II protein expression levels, and increased p62 expression in HK-2 cells compared with the H/R group (Fig. 6A). miR-30a-5p mimic transfection enhanced, whereas miR-30a-5p inhibitor transfection partly reversed, the effect of ATG16 knockdown on the expression of LC3-II (Fig. 6A). Compared with cells in the H/R group, ATG16 knockdown significantly decreased the number of LC3 punctae and decreased cell apoptosis (Fig. 6B and C). miR-30a-5p mimic enhanced, but miR-30a-5p inhibitor reversed, the effect of ATG16 knockdown on the number of LC3 punctae and apoptosis compared with the H/R + ATG16 siRNA group (Fig. 6B and C). Taken together, these results indicate that miR-30a-5p may mediate HK-2 cell autophagy in renal I/R injury by directly targeting Beclin-1 to modulate ATG16 expression.

\section{Discussion}

AKI is one of the most common complications in hospitalized patients. It is defined as a sudden decline in renal function, including cell death and inflammation in the proximal tubule (1). The underlying mechanism of AKI has not been fully elucidated (28). Kidney $\mathrm{I} / \mathrm{R}$ injury is a major cause of AKI $(1,29)$. Data from the present study demonstrated a significant decrease of miR-30a-5p expression, along 


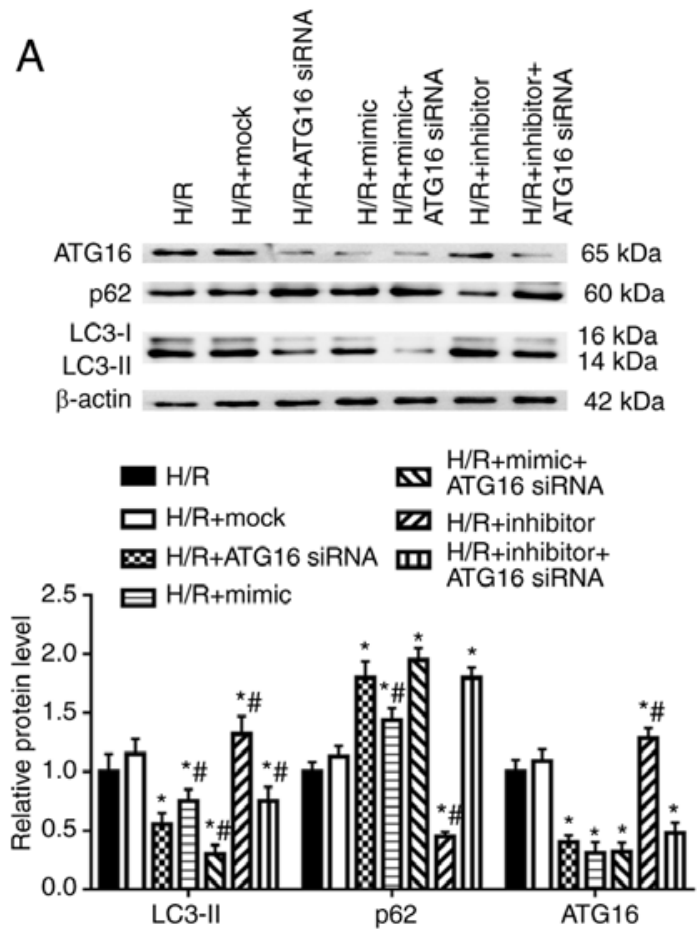

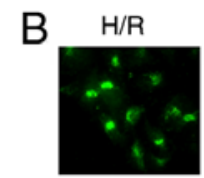

$\mathrm{H} / \mathrm{R}+$ mimic + ATG16 siRNA
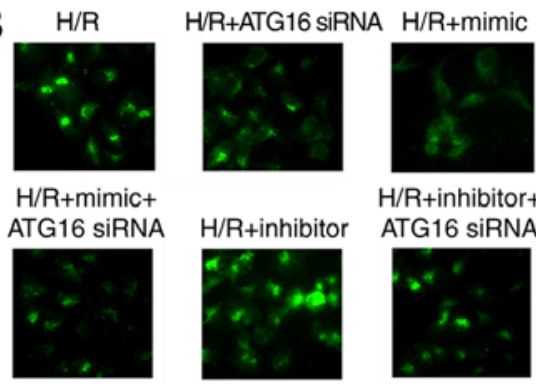

$\mathrm{H} / \mathrm{R}$ +inhibitorATG16 siRNA
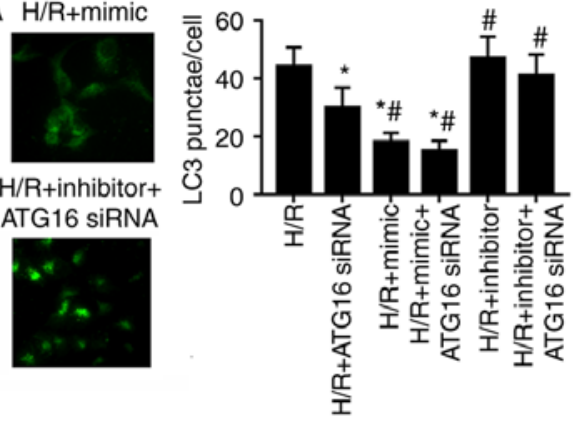

C

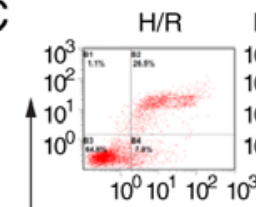

H/R+ATG16 siRNA H/R+mimic
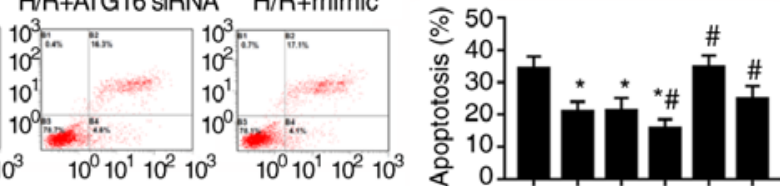

$\mathrm{PI}$

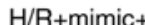

$\mathrm{H} / \mathrm{R}+$

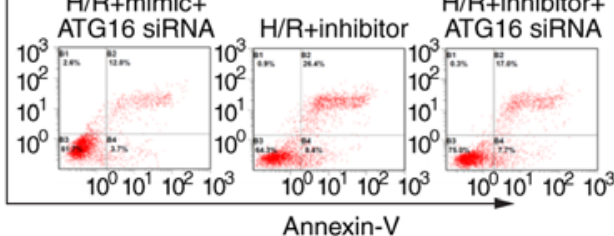

受

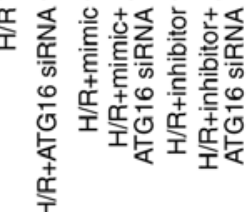

Figure 6. Beclin-1 contributes to HK-2 cell autophagy by modulating ATG16 expression. (A) HK-2 cells were transfected with ATG16 siRNA, miR-30a-5p mimic, miR-30a-5p inhibitor, or a combination of ATG16 siRNA with miR-30a-5p mimic or miR-30a-5p inhibitor, and then exposed to H/R injury. Protein expression levels were determined by western blot analysis $(\mathrm{n}=3)$. (B) Immunofluorescence staining was performed to detect LC3 punctae in HK-2 cells $(n=3$; magnification, $x 40)$. (C) Cell apoptosis was analyzed by flow cytometry following staining for Annexin V-FITC/PI. ( $n=3)$. " $P<0.05$ vs. H/R ${ }^{\#} \mathrm{P}<0.05$ vs. H/R + ATG16 siRNA. ATG16, autophagy-related gene16; H/R, hypoxia/reoxygenation; miR, microRNA; siRNA, small interfering RNA.

with upregulated expression of autophagy-related proteins LC3-II and Beclin-1 and decreased p62 expression, in mice with renal I/R injury and in HK-2 cells exposed to hypoxic conditions in vitro. It was also revealed that miR-30a-5p directly interacted with the 3'-UTR of Beclin-1, and that Beclin-1 effectively promoted cell autophagy by enhancing ATG16 levels. These data suggested that Beclin-1/ATG16 signaling may be a novel and promising downstream target of miR-30a-5p for therapeutic intervention in ischemic kidney injury. Autophagy may serve as a cellular homeostatic mechanism under stress conditions, including $H / R$ injury (27). Thus, in the current study, autophagy was examined by detecting the expression of LC3-II, Beclin-1 and p62, as well as by the LC3 punctae analysis. The I/R-injured mice showed increased LC3-II and Beclin-1, and decreased p62 protein expression levels. Similar results were observed in H/R-exposed HK-2 cells in vitro.

miRNAs are important in the maintenance of normal cellular functions, and dysregulation of miRNAs can result in a number of pathological states, including cellular differentiation, proliferation and apoptosis (30). Several studies have reported that miRNAs regulate tubular epithelial cell growth, apoptosis and renal injury $(31,32)$. Studies have also demonstrated that miR-30a-5p may regulate mitochondrial dynamics and autophagy (33), and it may also promote replication of porcine circovirus type 2 by enhancing autophagy (34). The present study data demonstrated that administration of miR-30a-5p mimic markedly decreased HK-2 cell apoptosis, downregulated expression of LC3-II and Beclin-1, and enhanced p62 expression in H/R-exposed
HK2 cells. Conversely, transfection with a miR-30a-5p inhibitor enhanced autophagy of H/R exposed HK-2 cells; the miR-30a-5p inhibitor had little effect on cell apoptosis. Several studies have associated dysregulated miRNAs not only to the pathogenesis of kidney injury but also to renal fibrosis (35-37). Li et al (38) reported that miR-30 expression was significantly inhibited by TGF- $\beta 1$ in the kidney fibroblast, and miR-30 was downregulated in renal fibrosis. Adenovirus-mediated upregulation of miR-30 in the kidney fibroblast significantly reduced unilateral ureteral obstruction-induced renal fibrosis by targeting SRY-box transcription factor 9 in mouse models (38). Unfortunately, the role of miR-30a-5p in renal fibrosis was not examined in the present study; we hypothesized that miR-30a-5p may affect renal fibrosis in the I/R model.

miRNAs conduct their biological function by binding to their target molecules (39). The mechanism of miR-30a-5p in ischemic kidney injury is unclear, and bioinformatic tools [microRNA.org (25), EIMMo miRNA target prediction (24) and TargetScan] were used in the present study to search for potential targets of miR-30a-5p. The results from many tools identified Beclin-1 to be an important element of autophagy that may be associated with the development of ischemic kidney injury (40). In a previous study, Beclin-1, which was identified as a target gene of miR-30a-5p, was shown to serve a crucial role in the drug-resistance of small cell lung cancer (16). In the present study, miR-30a-5p was shown to regulate autophagy of I/R injury renal by targeting Beclin-1.

A previous study revealed that Beclin-1 and the ATG5-ATG12-ATG16 complex serve important roles in 
autophagy of thyroid papillary carcinoma cells (41) and are involved in initial autophagosome formation (42). To clarify the mechanism underlying the positive effects of Beclin-1 on cell apoptosis and autophagy, the expression of ATG16 was examined in the present study. In accordance with our hypothesis, ATG16 expression was significantly upregulated in the renal I/R injury mouse models and in the H/R-exposed HK-2 cells. Beclin-1 positively regulated and miR-30a-5p negatively modulated ATG16 expression. Further analysis of the mechanism revealed that ATG16 siRNA significantly decreased HK-2 cell apoptosis, downregulated LC3-II expression and the number of LC3 punctae, and promoted p62 expression. These results demonstrated that Beclin-1 may regulate autophagy in H/R injured HK2 cells by regulating ATG16 expression.

In conclusion, the present data indicated that miR-30a-5p may moderate renal I/R injury by inhibiting autophagy and apoptosis. Furthermore, mechanistic analysis demonstrated that miR-30a-5p directly interacted with Beclin-1, and ATG16 was involved in this process. Collectively, our data suggested that miR-30a-5p may regulate autophagy after renal I/R injury via the Beclin-1/ATG16 pathway. These results may provide a novel therapeutic approach to combat ischemic kidney injury.

\section{Acknowledgements}

Not applicable.

\section{Funding}

No funding was received.

\section{Availability of data and materials}

The datasets used and/or analyzed during the current study are available from the corresponding author on reasonable request.

\section{Authors' contributions}

YF conceived and designed the study, performed the cell experiments and was a major contributor to the writing of the manuscript. LZ performed the animal experiments and helped write the manuscript. WH designed the study, performed the cell experiments and reviewed the manuscript. YF, LZ and WH confirmed the authenticity of all the raw data. All authors read and approved the final manuscript.

\section{Ethics approval and consent to participate}

The Ethics Committee of the General Hospital of Central Theater Command (Wuhan, China) approved this study, which followed the regulatory standards of the National Institutes of Health guide for the care and use of laboratory animals.

\section{Patient consent for publication}

Not applicable.

\section{Conflict of interest}

The authors declare that they have no conflict of interest.

\section{References}

1. Ronco C, Bellomo R and Kellum JA: Acute kidney injury. Lancet 394: 1949-1964, 2019.

2. Zhu X, Li W and Li H: miR-214 ameliorates acute kidney injury via targeting DKK3 and activating of Wnt/ $\beta$-catenin signaling pathway. Biol Res 51: 31, 2018.

3. Basile DP, Anderson MD and Sutton TA: Pathophysiology of acute kidney injury. Compr Physiol 2: 1303-1353, 2012.

4. Chun N, Coca SG and He JC: A protective role for microRNA-688 in acute kidney injury. J Clin Invest 128: 5216-5218, 2018.

5. Zhang L, Xu Y, Xue S, Wang X, Dai h, Qian J, Ni Z and Yan Y: Implications of dynamic changes in miR-192 expression in ischemic acute kidney injury. Int Urol Nephrol 49: 541-550, 2017.

6. Levine B and Kroemer G: Autophagy in the pathogenesis of disease. Cell 132: 27-42, 2008

7. Kim KH and Lee MS: Autophagy-a key player in cellular and body metabolism. Nat Rev Endocrinol 10: 322-337, 2014.

8. Kaushal GP and Shah SV: Autophagy in acute kidney injury. Kidney Int 89: 779-791, 2016.

9. Tian R, Wang P, Huang L, Li C, Lu Z, Lu Z, Wu A, Bao K, Mao W, Huang Q and Xu P: Sanqi oral solution ameliorates renal ischemia/reperfusion injury via reducing apoptosis and enhancing autophagy: Involvement of ERK/mTOR pathways. Front Pharmacol 11: 537147, 2020.

10. Cui J, Bai X and Chen X: Autophagy and acute kidney injury. Adv Exp Med Biol 1207: 469-480, 2020.

11. Ham O, Lee SY, Lee CY, Park JH, Lee J, Seo HH, Cha MJ, Choi E, Kim S and Hwang KC: Let-7b suppresses apoptosis and autophagy of human mesenchymal stem cells transplanted into ischemia/reperfusion injured heart 7 by targeting caspase-3. Stem Cell Res Ther 6: 147, 2015.

12. Wilflingseder J, Jelencsics K, Bergmeister h, Sunzenauer J, Regele h, Eskandary F, Reindl-Schwaighofer R, Kainz A and Oberbauer R: miR-182-5p inhibition ameliorates ischemic acute kidney injury. Am J Pathol 187: 70-79, 2017.

13. Ren GL, Zhu J, Li J and Meng XM: Noncoding RNAs in acute kidney injury. J Cell Physiol 234: 2266-2276, 2019.

14. Wang C, Cai L, Liu J, Wang G, Li H, Wang X, Xu W, Ren M, Feng L, Liu P and Zhang C: MicroRNA-30a-5p inhibits the grow th of renal cell carcinoma by modulating GRP78 expression. Cell Physiol Biochem 43: 2405-2419, 2017.

15. Chen Z, Zhang J, Zhang Z, Feng Z, Wei J, Lu J, Fang Y, Liang Y, Cen J,Pan Y, et al: The putative tumor suppressormicroRNA-30a-5p modulates clear cell renal cell carcinoma aggressiveness through repression of ZEB2. Cell Death Dis 8: e2859, 2017.

16. Yang X, Bai F, Xu Y, Chen Y and Chen L: Intensified Beclin-1 mediated by low expression of Mir-30a-5p promotes chemoresistance in human small cell lung cancer. Cell Physiol Biochem 43: 1126-1139, 2017.

17. Yang Y, Li Y, Chen X, Cheng X, Liao Y and Yu X: Exosomal transfer of miR-30a between cardiomyocytes regulates autophagy after hypoxia. J Mol Med (Berl) 94: 711-724, 2016.

18. Guo D, Ma J, Yan L, Li T, Li Z, Han X and Shui S: Down-regulation of lncrna MALAT1 attenuates neuronal cell death through suppressing Beclin1-dependent autophagy by regulating Mir-30a in cerebral ischemic stroke. Cell Physiol Biochem 43: 182-194, 2017.

19. National Research Council (US) Institute for Laboratory Animal Research: Guide for the care and use of laboratory animals. Washington DC: National Academies Press (US); 1996.

20. Sun Y, Zhang Y, Zhao D, Ding G, Huang S, Zhang A and Jia Z: Rotenone remarkably attenuates oxidative stress, inflammation, and fibrosis in chronic obstructive uropathy. Mediators Inflamm 2014: 670106, 2014

21. Livak KJ and Schmittgen TD: Analysis of relative gene expression data using real-time quantitative PCR and the 2(-Delta Delta C(T)) method. Methods 25: 402-408, 2001.

22. Sun J, Chen X, Liu T, Jiang X, Wu Y, Yang S, Hua W, Li Z, Huang h, Ruan X and Du X: Berberine protects against palmitate-induced apoptosis in tubular epithelial cells by promoting fatty acid oxidation. Med Sci Monit 24: 1484-1492, 2018.

23. Liu F, Ai FY, Zhang DC, Tian L, Yang ZY and Liu SJ: LncRNA NEAT1 knockdown attenuates autophagy to elevate 5-FU sensitivity in colorectal cancer via targeting miR-34a. Cancer Med 9: 1079-1091, 2019

24. Hausser J, Berninger P, Rodak C, Jantscher Y, Wirth S and Zavolan M: MirZ: An integrated microRNA expression atlas and target prediction resource. Nucleic Acids Res 37: W266-W272, 2009. 
25. Betel D, Wilson M, Gabow A, Marks DS and Sander C: The microRNA.org resource: Targets and expression. Nucleic Acids Res 36: D149-D153, 2008.

26. Kang R, Zeh HJ, Lotze MT and Tang D: The Beclin 1 network regulates autophagy and apoptosis. Cell Death Differ 18: 571-580, 2011.

27. Wang IK, Sun KT, Tsai TH, Chen CW, Chang SS, Yu TM, Yen TH, Lin FY, Huang CC and Li CY: MiR-20a-5p mediates hypoxia-induced autophagy by targeting ATG16L1 in ischemic kidney injury. Life Sci 136: 133-141, 2015.

28. Jiang L, Liu XQ, Ma Q, Yang Q, Gao L, Li HD, Wang JN, Wei B, Wen J, Li J, et al: Hsa-miR-500a-3P alleviates kidney injury by targeting MLKL-mediated necroptosis in renal epithelial cells. FASEB J 33: 3523-3535, 2019.

29. Shen WC, Chou YH, Huang HP, Sheen JF, Hung SC and Chen HF: Induced pluripotent stem cell-derived endothelial progenitor cells attenuate ischemic acute kidney injury and cardiac dysfunction. Stem Cell Res Ther 9: 344, 2018.

30. Liu N, Jiang N, Guo R, Jiang W, He QM, Xu YF, Li YQ, Tang LL, Mao YP, Sun Y and Ma J: MiR-451 inhibits cell growth and invasion by targeting MIF and is associated with survival in nasopharyngeal carcinoma. Mol Cancer 12: 123, 2013.

31. Lorenzen JM, Haller H and Thum T: MicroRNAs as mediators and therapeutic targets in chronic kidney disease. Nat Rev Nephrol 7: 286-294, 2011.

32. Chau BN, Xin C, Hartner J, Ren S, Castano AP, Linn G, Li J, Tran PT, Kaimal V, Huang X, et al: MicroRNA-21 promotes fibrosis of the kidney by silencing metabolic pathways. Sci Transl Med 4: 121ra118, 2012

33. Schwienbacher C,FocoL,Picard A, Corradi E, Serafin A,Panzer J, Zanigni S, Blankenburg h, Facheris MF, Giannini G, et al: Plasma and white blood cells show different miRNA expression profiles in parkinson's disease. J Mol Neurosci 62: 244-254, 2017.

34. Wang $\mathrm{X}, \mathrm{Xu} \mathrm{X}$, Wang $\mathrm{W}, \mathrm{Yu} \mathrm{Z}$, Wen L, He K and Fan $\mathrm{H}$ : MicroRNA-30a-5p promotes replication of porcine circovirus type 2 through enhancing autophagy by targeting 14-3-3. Arch Virol 162: 2643-2654, 2017.
35. Sun T, Liu Y,Liu L and Ma F: MicroRNA-544 attenuates diabetic renal injury via suppressing glomerulosclerosis and inflammation by targeting FASN. Gene 723: 143986, 2020.

36. Wu J, Huang Q, Li P, Wang Y, Zheng C, Lei X, Li S, Gong W, Yin B, Luo C, et al: MicroRNA-145 promotes the epithelial-mesenchymal transition in peritoneal dialysis-associated fibrosis by suppressing fibroblast growth factor 10 . J Biol Chem 294: 15052-15067, 2019.

37. Fan $\mathrm{Y}$, Chen $\mathrm{H}$, Huang $\mathrm{Z}$, Zheng $\mathrm{H}$ and Zhou J: Emerging role of miRNAs in renal fibrosis. RNA Biol 17: 1-12, 2020.

38. Li H, Cai H, Deng J, Tu X, Sun Y, Huang Z, Ding Z, Dong L, Chen J, Zang Y and Zhang J: TGF- $\beta$-mediated upregulation of Sox9 in fibroblast promotes renal fibrosis. Biochim Biophys Acta Mol Basis Dis 1864: 520-532, 2018.

39. Ebert MS and Sharp PA: Roles for microRNAs in conferring robustness to biological processes. Cell 149: 515-524, 2012.

40. Xie Y, Jiang D, Xiao J, Fu C, Zhang Z, YeZ and Zhang X: Ischemic preconditioning attenuates ischemia/reperfusion-induced kidney injury by activating autophagy via the SGK1 signaling pathway. Cell Death Dis 9: 338, 2018.

41. Liu Z, Zeng W, Wang S, Zhao X, Guo Y, Yu P, Yin X, Liu C and Huang T: A potential role for the Hippo pathway protein, YAP, in controlling proliferation, cell cycle progression, and autophagy in BCPAP and KI thyroid papillary carcinoma cells. Am J Transl Res 9: 3212-3223, 2017.

42. Bejarano E, Yuste A, Patel B, Stout RF Jr, Spray DC and Cuervo AM: Connexins modulate autophagosome biogenesis. Nat Cell Biol 16: 401-414, 2014. 